\title{
De la integración vertical al mercado: el taller de artes gráficas de la Compañía General de Fósforos en las primeras décadas del siglo $X^{*}$
}

MARÍA SILVIA BADOZA**

Resumo: Este artigo analisa a gráfica da Compañía General de Fósforos, uma sociedade anônima que, em sua integração vertical, incorporou a atividade de artes gráficas para a impressão litográfica nas caixas de fósforo. Nos interessamos pelas estratégias de inversão para analisar o dessenvolvimento deste estabelecimento de imprensa no conjunto da Compañía e em um contexto de expansão da indústria gráfica na Argentina.

Abstract: This paper studies the case of Compañía General de Fósforos, a big shareholders company and manufacturer of matches that, as part of its process of vertical integration, set up a printing shop for the lithographed matchbox labels. The focus is placed on investment strategies that contributed to the industrial development of this printing shop within the Company, in a context of expansion of the printing industry in Argentina.

Palavras chave: Indústria gráfica. Compañía General de Fósforos. Buenos Aires. Key words: Printing industry. Compañía General de Fósforos. Buenos Aires.

\section{Introducción}

En Argentina, el sector de artes gráficas tuvo un desarrollo temprano y dirigido al mercado interno. Procesaba materia prima importada - a excepción de unos pocos papeles fabricados en el país - y utilizaba tecnología adquirida en el exterior y una mano de obra altamente calificada con elevados salarios. Sin embargo,

* Este trabajo contó con el apoyo del FONCYT/ANPCYT en el marco del proyecto PICT13934.

** Profesional principal de CONICET. PEHESA/Instituto Ravignani, UBA. E-mail: silviabadoza@fibertel.com.ar 
quienes se dedicaron a historiar el desarrollo industrial argentino no se ocuparon del sector artes gráficas ni de sus empresas más representativas. ${ }^{1}$ Tampoco contamos con un nutrido corpus de estudios como en Inglaterra, Francia y EEUU, que contribuyeron desde una perspectiva del trabajo a reinterpretar, en el contexto de industrialización de las dos décadas finales del siglo XIX y las primeras del XX, el desarrollo de la industria y la fase de cambio tecnológico, así como también los procesos y la organización del trabajo. ${ }^{2}$ Esta ausencia es más llamativa teniendo en cuenta que, en las últimas décadas, la historiografía que se ha interesado en la prensa gráfica argentina, enfocó el desarrollo de las empresas periodísticas y el uso de nuevas tecnologías para explicar los cambios de estas producciones culturales (formatos y aumentos en las tiradas de los diarios). ${ }^{3}$

Este artículo centra la atención en la incorporación temprana de la Compañía General de Fósforos a la actividad de artes gráficas, con un establecimiento ubicado en el industrial barrio de Barracas al sudeste de la ciudad de Buenos Aires, para la impresión de la tradicional litografía en las cajas de fósforos. De hecho, esta imprenta fue la primera integración vertical que coincidió temporalmente con el inicio de la fabricación del vástago de cerilla. Además, la ligazón con la rama industrial gráfica prosiguió después de la formación, en el año 1929, de la Compañía General Fabril Financiera, una nueva sociedad anónima industrial general, que

1 Véase Alejandro, Carlos Díaz. Ensayos sobre la historia económica argentina. Buenos Aires: Amorrortu, 1975; Dorfman, Adolfo. Historia de la industria argentina. Buenos Aires: Solar Hachette, 1970; Korol, Juan C. La Industria 1850-1914. En: Academia Nacional de la Historia. Nueva Historia de la Nación Argentina. Buenos Aires: Planeta (vol. 6), 1997, p. 147-171. Schvarzer, Jorge. La industria que supimos conseguir. Buenos Aires: Planeta, 1996.

2 Duffy. The Skilled Compositor, 1850-1914. An Aristocrat among Working Men. Aldershot: Ashgate, 2000; Kealey, G. Work Control, The Labour Process, and NineteenthCentury Canadian Printers. En: Heron, C. y Storey, R. (eds). On The Job. Confronting the Labour Process in Canada. Montreal: McGill-Queen's University Press, 1988; Zeitlin, J. Craft control and the division of labour: engineers and compositors in Britain, 1890-1930. Cambridge Journal of Economics, 3, p. 263-274, 1979; Zerker, S. Printers, Technology and Unionism. En: Lundy, K. y Warme, B. (eds.). Work in the Canadian Context: Continuity Despite Change. Toronto: Butterworths, 1986.

3 Ulanovsky, Carlos. Paren las rotativas. Historia de los grandes diarios, revistas y periodistas argentinos. Buenos Aires: Espasa, 1997; Sabato, Hilda. La politica en las calles: entre el voto y la movilización. Buenos Aires 1862-1880. Buenos Aires: Sudamericana, 1998; Saítta, Sylvia. Regueros de tinta. El diario Crítica en la década del '20. Buenos Aires: Sudamericana, 1998; Tato, María I.. Viento de Fronda. Liberalismo, conservadurismo y democracia en la Argentina, 1911-1932. Buenos Aires: Siglo XXI Editores de Argentina, 2004. 
reunió las explotaciones del ramo de las artes gráficas, textil de algodón y aceitera y los intereses del papel.

El objetivo del estudio es explicar el desarrollo de la imprenta en el contexto del conjunto de la Compañía General de Fósforos, ${ }^{4}$ y a su vez, en el marco de expansión de la rama industrial de las artes gráficas. Para ello exploramos el período que se extiende entre 1889 y 1921. La fecha inicial coincide con la formación de la Compañía General de Fósforos y los comienzos del taller de artes gráficas, mientras que la de finalización está relacionada con un nuevo rumbo de la actividad gráfica de la Compañía con la compra del taller de Ricardo Radaelli en 1921. A partir de esa fecha, las publicaciones periódicas de gran tiraje fueron parte de la producción más característica de los talleres gráficos de la Compañía, llegando a concentrar la producción de aproximadamente el 80\% de las revistas que circulaban en el país.

La primera parte del estudio refiere al desarrollo de la rama industrial de artes gráficas desde mediados del siglo XIX. En el segundo apartado nos ocupamos del origen y desarrollo de la empresa. La tercera parte presenta la evolución de las inversiones en terreno, edificio y maquinaria realizadas en el establecimiento de Barracas. Exploramos las incorporaciones anuales en capital fijo para comprender las estrategias de inversión en relación con la integración vertical en la fabricación de las cajas de fósforos y en la diversificación productiva del establecimiento. En la cuarta parte analizamos la composición y evolución de las ventas del establecimiento de imprenta. ${ }^{5}$

4 Para un análisis de las historias de empresas en Argentina entre 1880 y 1930 véase Guy, Donna. Refinería Argentina, 1888-1930: límites de la tecnología azucarera en una economía periférica. Desarrollo Económico, Buenos Aires, n. 111, p. 353-373, octubre-diciembre de 1988; Gutiérrez, Leandro y Korol, Juan C. Historias de empresas y crecimiento industrial en la Argentina. El caso de la Fábrica Argentina de Alpargatas. Desarrollo Económico, Buenos Aires, p. 401-424; Badoza, Silvia. Archivos de empresas: la Compañía General de Fósforos. En: CD VII Jornadas Interescuelas Departamentos de Historia. Neuquén: Universidad Nacional del Comahue, 1999; Barbero, María I.. Mercados, redes sociales y estrategias empresariales en los orígenes de los grupos económicos. De la Compañía General de Fósforos al Grupo Fabril, 1889-1929. Estudios Migratorios Latinoamericanos, Buenos Aires, n. 44, p. 119-145, 2000; Gilbert, Jorge. El Grupo Tornquist entre la expansión y las crisis de la economía argentina en el siglo XX. Ciclos, n. 25-26, p. 65-91, 2003.

5 Las fuentes de este estudio provienen del trabajo de María Silvia Badoza de recuperación y preservación del archivo de empresa de la Compañía General de Fósforos y Fabril Financiera. Este archivo se encuentra en el PEHESA/Instituto Emilio Ravignani, Facultad de Filosofía y Letras, UBA. 


\section{La industria gráfica}

La industria gráfica se inició en Buenos Aires a mediados del siglo XIX con diarios y publicaciones periódicas. El desarrollo del mercado de estos productos, típicamente urbanos, puede considerarse una consecuencia del crecimiento demográfico y del aumento de la complejidad social y cultural de la ciudad. Con el desarrollo del sistema educativo, a partir de 1880, la alfabetización se extendió a amplios sectores de la sociedad. Esto produjo un aumento del público lector, que demandaba diarios, publicaciones científicas y literarias, libros y revistas de interés general. La creciente demanda de material impreso motorizó la expansión de la industria.

A partir de 1880 la cantidad de talleres de imprenta aumentó rápidamente en Buenos Aires, transformándola en un centro de las artes gráficas. El censo de 1895 registraba la cantidad de 223 talleres que empleaban 3.609 personas. En 1914 la industria gráfica había crecido más y contaba con 511 talleres y 7.675 trabajadores. ${ }^{6}$ Los datos censales de 1895 y 1914, dos años que abarcan la mayoría del período de tiempo considerado, muestran la expansión de la industria: la cantidad de talleres de imprenta casi se triplicó y la mano de obra ocupada se duplicó. No tenemos más información estadística sobre el desarrollo de la industria hasta 1935, cuando un nuevo censo registró 916 talleres y 19.487 trabajadores en la ciudad de Buenos Aires. Durante este largo período la expansión de la industria gráfica fue especialmente intensa en la década de $1920 .{ }^{7}$

Los datos censales, junto a otras fuentes industriales, muestran una gran cantidad de pequeños talleres que empleaban unos pocos trabajadores y revelan la existencia de unas pocas empresas grandes con gran concentración de capital y mano de obra. Paralelamente, se produjo una concentración geográfica de talleres multigráficos desde la Avenida de Mayo hasta la zona sudeste de la ciudad; en el barrio de Barracas y a pocas cuadras de distancia unos de otros estaban ubicados: la Compañía Sudamericana de Billetes de Banco, la Casa Peuser, Guillermo Kraft y la Compañía General de Fósforos.

Hacia 1880 los dos sectores en que se dividía la rama de la imprenta, periódicos y obra/comercial, estaban instalados y en

6 Segundo Censo Nacional de 1895, Tomo III, Cap. XI; Tercer Censo Nacional de 1914, capítulo 7, Industrias; Censo Industrial de 1935, Tomo I, Cap. III.

7 Villanueva, J. El origen de la industrialización argentina. Desarrollo Económico. Revista de Ciencias Sociales, 47, p. 451-476, 1972. 
muchos casos coexistiendo en una misma empresa gráfica. La gama de productos era muy variada e incluía diarios, publicaciones periódicas, revistas, libros, tarjetas personales y comerciales, publicidad y naipes. A estos productos tradicionales se agregaban distintos tipos de publicaciones comerciales, como guías, catálogos de temporada para las tiendas de departamentos, etiquetas de cigarrillos, las tradicionales litografías de las cajas de fósforos, etiquetas de aduana para productos de exportación, libros de contabilidad blancos y rayados. En cambio, la publicación de libros era limitada principalmente por la tarifa aduanera, que imponía un derecho de importación menor a los pagados por materias primas utilizadas en el sector industrial.

La estructura y la producción de los establecimientos se tornaron cada vez más complejas. Para comprender plenamente el funcionamiento de la industria gráfica es necesario tomar en cuenta tanto las tecnologías utilizadas como la gran diversidad de los productos. Cada producto (diarios, catálogos, tarjetas, publicidad y folletos, revistas o naipes) daba origen a diferentes procesos de trabajo y organizaciones productivas. Algunos talleres desarrollaban todas las etapas de la producción (composición, impresión y encuadernación). Otros se dedicaban a una o dos de ellas. No solamente la naturaleza de los productos, sino también sus requerimientos de calidad y la escala de producción influían fuertemente en la organización de los talleres. Algunos como Kraft, Peuser, Rosso y Radaelli eran grandes establecimientos completos de variada producción. Otros se especializaban en algunos productos específicos, como publicidad y catálogos. Dispersos por toda la ciudad había muchas pequeñas imprentas que podían tomar cualquier tipo de trabajo, siempre en escaso volumen.

La vía más generalizada del desarrollo de los talleres de artes gráficas estuvo dada por aquellos individuos salidos de la producción, es decir, hombres del oficio, que acumularon un pequeño capital e instalaron su propio taller. Este camino fue el que recorrieron la mayoría de los propietarios, no sólo en el período que estamos considerando sino hasta bien entrado el siglo $\mathrm{XX}, \mathrm{y}$ determinó para la industria gráfica un perfil donde abundaban los pequeños empresarios y no faltaba la producción familiar.

En cambio, la inserción en la actividad de la imprenta como parte de la integración vertical, camino seguido por la Compañía, constituyó un hecho excepcional por varias décadas en la rama industrial. Por cierto, esta incorporación a la actividad gráfica fue 
imitada muy posteriormente por las compañías tabacaleras, que instalaron sus propios talleres a partir de la compra de destacados establecimientos litográficos de Buenos Aires. ${ }^{8}$

Los industriales del sector, pese a su heterogeneidad, lograron conformar a finales de 1904 la Sección Artes Gráficas de la UIA. Esta cámara empresarial concentró su acción básicamente alrededor de dos cuestiones: una la arancelaria, otra la obrera. En cuanto a los aranceles, los dueños de imprenta pidieron, en reiteradas oportunidades, la derogación de gravámenes a la importación de materias primas y maquinarias, oponiéndose a la política por la que se liberaba del pago de derechos aduaneros a los libros importados. ${ }^{9}$ Frente a la problemática laboral, la Sección Artes Gráficas tuvo una posición diferenciada de la seguida tradicionalmente por la entidad industrial, que se manifestaba intransigente en la negociación con los sindicatos, a los que no reconocían y trataban de mantener alejados de sus fábricas, considerando la legislación laboral como una intromisión de los organismos estatales en una relación privada entre industriales y obreros. La rama de las Artes Gráficas constituyó una excepción, tanto desde la perspectiva de los empresarios como desde la de los trabajadores, pues desde 1907 ambos actores mantuvieron una relación institucionalizada mediante la firma de un convenio que se renovó en cuatro oportunidades y que establecía una tarifa salarial, un reglamento de trabajo y una comisión mixta encargada de solucionar los conflictos en las imprentas. Incluso desde 1915 hubo un cierto reconocimiento del sindicato. ${ }^{10}$ En suma, las relaciones

8 Piccardo adquirió para fabricar las marquillas de cigarrillos el establecimiento gráfico de Podestarelli y Bonfiglio, mientras que la Compañía Nacional de Tabacos (desde 1933 Compañía Nobleza de Tabacos) compró la imprenta y litografía de Alejandro Bianchi y Cía.

9 En 1908 los dueños de imprenta pedían la aprobación de un derecho de importación que fuera el doble que el que gravaba al papel en blanco para obras, aplicable a los libros de autores residentes en Argentina y que enviaban sus obras a imprimir en el extranjero. En esta discusión el empresariado gráfico perdía fuerza para imponer su criterio, porque, en general, desde el poder público argumentaban que tal gravamen, al aumentar el precio de la edición de libros, iba en contra del desarrollo cultural del país y más concretamente de la instrucción pública de la población. Boletín de La Unión Industrial Argentina, Buenos Aires, Año XXII, n. 480, p. 37, 15 de diciembre de 1908.

10 Badoza, María Silvia. Skilled Work and Labour Careers in the Argentine Printing Industry, 1880-1930. En: Brown, J.; Leewuwen, M. van y Mitch, D. (eds.). Origins of the Modern Career. Aldershot: Ashgate, 2004, p. 164-187. Patrones, capataces y trabajadores en la industria gráfica: un estudio de caso: Ortega y Radaelli, 19011921. Secuencia. Revista de Historia y Ciencias Sociales, México, n. 50, p. 46-81, 2001. 
institucionalizadas evitaron, durante el período de vigencia del convenio - desde 1907 a 1919 - el estallido de huelgas generales en la rama de las artes gráficas.

\section{Génesis de la Compañía General de Fósforos}

La Compañía General de Fósforos, entre 1889 y 1929, constituye un ejemplo interesente de sociedad anónima industrial que realizó una integración vertical relacionada con su principal rubro productivo, los "fósforos de cerilla". Este eslabonamiento productivo quedó plasmado en las inversiones realizadas en dicho período en artes gráficas, papel, estearina y el complejo algodonero (desmote, hilado y aceite). La Sociedad Anónima se origina a partir de la fusión de los tres establecimientos existentes en la ciudad de Buenos Aires: Barracas al Norte (Bolondo, Lavigne y Cía.); Barracas al Sur (A. Dellachá y hermano) y Belgrano (Francisco Lavaggi e hijo). Entre los socios fundadores se encontraban los antiguos propietarios de los establecimientos fosforeros. El capital social original de 2.000.000 moneda nacional fue acrecentado y totalmente integrado en seis oportunidades durante los años de existencia de la Compañía General de Fósforos. La mayor expansión se produjo a partir de 1900. Entre ese año y 1908 casi se duplicó, y entre esta última fecha y 1919 se incrementó en un 370\%.

Desde 1889 hasta 1929 la principal actividad productiva de la Compañía fue la fosforera; la evolución de las inversiones y la diversificación productiva estuvieron relacionadas con ese rubro. Hasta la Primera Guerra Mundial la Compañía General de Fósforos dependió de insumos importados para la fabricación de los fósforos de cerilla. La contienda mundial fue una coyuntura crítica para el abastecimiento de materias primas e insumos desde el exterior, pero también de clivaje en las respuestas dadas por los directivos de Compañía General de Fósforos. La política expansiva, que comprende el período 1888-1929, quedó plasmada en diversas implantaciones fabriles, que podemos resumir así: fábricas de fósforos en Avellaneda, Paraná, Tucumán, Santa Fe, Córdoba, Corrientes y Montevideo; talleres gráficos en Barracas y Montevideo; establecimiento de estearina en La Plata; desmotadora de algodón y fábrica de aceite de algodón, ambas ubicadas en La Liguria (Chaco) y, finalmente, la hilandería de Bernal. En 1926 el establecimiento de papel ubicado en Bernal pasó a formar parte de la nueva concentración empresaria: La Papelera Argentina. Mientras que en 1927 acrecentó sus intereses en el complejo 
algodonero al formar la CICMAT (Compañía Italo-Argentina de Materiales Textiles) para la comercialización de algodón.

Durante el período 1888-1929 la Compañía General de Fósforos dirigió sus inversiones a infraestructura (edificios industriales) y tecnología de la industria madre del fósforo y de cada una de las ramas industriales que desarrollaron durante sus cuarenta años de existencia. Si bien en los inicios los establecimientos pertenecientes a las ramas industriales del papel, textil, algodón e imprenta fueron instalados en función de la industria fosforera, en distintos momentos cada uno de ellos amplió la gama de productos destinados al mercado interno.

\section{El Establecimiento Artes Gráficas}

La primera sustitución, alcanzada inmediatamente después de constituirse la Sociedad Anónima, fue la relacionada con los envases de los fósforos:

Proponíase la Compañía implantar en el país una vasta empresa destinada al sostenimiento de una fábrica de cerillas y sus cajas, teniendo como anexo un taller de litografía destinado a la ornamentación policroma de aquellos. En el país era la primera vez que un taller semejante se establecía a expensas de una fábrica de fósforos, pues hasta entonces la impresión litográfica se hacía en Europa; la nueva disposición de las cosas mejoró el artículo y el primor de la factura, y esto fue debido a la atención exclusiva que se concedió a esta especialización del arte gráfico. ${ }^{11}$

El establecimiento Barracas al Norte reunió desde 1889 la fabricación de la cerilla o fósforo y las artes gráficas. Las instalaciones del taller litográfico comprendían la sección fabricación de cajas de fósforos y la sección comercio de la litografía. Esta última abarcaba el conjunto de técnicas y procesos que intervenían en la realización de un impreso: composición, grabado, impresión y encuadernación.

Para 1895 la firma había instalado el equipamiento para la producción de papel y cartulinas math: "Una de ellas, única que de su especie existe en la República Argentina, se encarga de preparar al que viene en bobinas o rollos, y otra que manipula el mismo artículo en resmas o cortado" ${ }^{12}$

11 Klett, Carlos Lix. Estudios sobre Producción, Comercio, Finanzas e Intereses Comerciales de la República Argentina. Buenos Aires, 1900, Vol. 1, p. 469.

12 Papel cuya superficie es alisada al extender una preparación de sulfato de barnices y colas en una o las dos caras, quedando listo para su impresión en colores. Burzaco, J. Fernández. Guía descriptiva de los principales establecimientos industriales de la República Argentina. Obra patrocinada por UIA, Buenos Aires, p. 257, 1895. 
Los talleres de impresión litográfica poseían una dotación de 21 máquinas, entre ellas seis para imprimir en color, una para broncear, dos para las impresiones fototípicas y una para moler los colores de las tintas, además de equipos fotográficos para la reducción de los dibujos y un stock de piedras para grabar las ilustraciones realizadas en técnicas de acuarela. Para el proceso de producción del estuche externo adquirieron, bajo licencia de exclusividad, dos máquinas para el barnizado y secado de las cartulinas impresas con la marca registrada de los fósforos.

En la sección fabricación de las cajitas los pliegos de cartulina impresa eran cortados manualmente con el sacabocados, un aparato que reproducía el formato del estuche antes de ser armado. El corte, armado y pegado de los cajoncitos interiores estaba mecanizado. Para estas operaciones habían instalado unas sesenta máquinas y otras sesenta pegaban las gomas que unían la caja interna con el estuche. Ya para 1895 la Compañía había instalado una máquina de tecnología europea para el armado de las cajitas: "La máquina en cuestión, difícil de describir por su complicado mecanismo, tiene cuatro punzones por los cuales arroja completamente concluidos: por el primero, a la izquierda, el estuche interno de la caja, por el segundo el externo, otro externo por el tercero, y otro interno por el cuarto. Excusado es decir que los estuches referidos salen pegados artificialmente, o lo que es lo mismo, sin necesidad de engrudo ni de goma.". ${ }^{13}$

A la vuelta del siglo XX, el edificio de Barracas, una vez que los empresarios decidieron centralizar la elaboración de fósforos en una moderna construcción en Avellaneda, fue adquiriendo la forma definitiva de establecimiento gráfico.

La sección comercial excedió prontamente las necesidades internas de la producción de etiquetas de fósforos, siendo su primer ensayo en el mercado la impresión de marquillas de cigarrillos. La capacidad instalada y la experiencia acumulada en la fabricación de etiquetas, embalajes y estuches para fósforos desde principios de siglo fueron aprovechadas por los empresarios para profundizar la reorientación de este tipo de producción hacia el mercado, transformándose en abastecedores de destacadas empresas industriales, comerciales y de servicios.

Paralelamente, iniciaron una diversificación productiva relacionada con la propaganda comercial: catálogos, afiches, carteles,

13 Burzaco, op. cit., p. 259. 
avisos publicitarios. La diversificación abarcó la producción de impresos relacionados con la actividad comercial y bancaria (letras de cambio y cheques) y para organismos estatales (nacionales y municipales) junto a empresas de servicios. Hacia 1903 imprimían para la Dirección de Correos y Telégrafos (formularios y anotadores de telegramas), sumándose en 1908 la Intendencia de Guerra y posteriormente la Aduana de la Capital (formularios de entrada y talonarios de órdenes de entrega). ${ }^{14}$

Hubo otras búsquedas de diversificación destinadas al mercado mediante la incursión en nuevas líneas de productos que requirieron abrir nuevas secciones en el edificio de Barracas, compra de maquinaria y construcciones. En el año 1905 comenzaron la fabricación de almanaques y blocks, al año siguiente iniciaron la fabricación de libros blancos y rayados. Entre 1907 y 1908 construyeron la sección naipes, compraron la maquinaria y comenzaron los ensayos de producción. ${ }^{15}$ Un año después, en 1910, la Compañía lanzó al mercado su propia marca de naipes, "Angelito", que se constituyó en un producto de consumo masivo como los fósforos.

En cuanto a la sección cuadernos, libros en blanco y rayados, los primeros venían produciéndose desde tiempo atrás; la parte de libros contables y de oficina, abierta recién en 1906, estuvo destinada al abastecimiento de empresas industriales, comerciales, bancarias y de servicios y la burocracia estatal. ${ }^{16}$ La Compañía entró tardíamente en esta producción, en comparación con Peuser y Kraft. En 1929, ya fuera del límite temporal de nuestro trabajo, el directorio de la empresa decidió realizar el camino inverso y cerrar la sección de libros blancos y rayados debido a su baja rentabilidad.

Hacia 1916 el establecimiento de artes gráficas ocupaba una superficie $15.900 \mathrm{~m}^{2}$, tenía una fuerza motriz instalada de $200 \mathrm{HP}$, distribuida por todo el edificio mediante motores eléctricos y empleaba una fuerza laboral de aproximadamente 900 obreros, compuesta por operarios calificados, mujeres y menores. El taller estaba organizado en cuatro secciones: la tipo-litografía con los talleres auxiliares de fotograbado y tricomía, cuadernos y libros en blanco y rayados, almanaques y blocks, naipes. ${ }^{17}$

14 Véase Compañía General de Fósforos, Libros Inventarios Generales, 1903-1919.

15 En 1909 manufacturaron 38.959 unidades de juegos de naipes ordinarios y 3510 finos, tipo Fló.

16 La sección fabricaba: libros diarios, mayores numerados, de actas, copiadores, borradores, libretas, índices, entre otros. En 1915 fabricaban para el Correo los libros de oficina, libros formularios de valijas y libros clasificación de valijas.

17 La Nación, Número Especial de la Independencia Argentina, Buenos Aires, p. 73, 1916. 
La actividad gráfica tomó un nuevo rumbo con la compra del taller de Ricardo Radaelli, que siguió funcionando en su emplazamiento original de la calle Paseo Colón entre 1921 y 1926, hasta su unificación con el otro más antiguo de la Compañía, instalado en el barrio de Barracas; máquinas y personal fueron trasladados en 1926 a este edificio de la calle California. La unión de ambos establecimientos llevó a la realización de inversiones en la remodelación y ensanche del edificio de la calle California. Entre 1925 y 1929 continuaron renovando maquinaria y completaron un ciclo de reformas en los talleres gráficos con la adopción de una nueva jerarquía de dirección en el establecimiento y la incorporación de una moderna contabilidad industrial para conocer la rentabilidad de cada una de las publicaciones y secciones del establecimiento. Desde 1929 el establecimiento de artes gráficas pasó a formar parte de la Compañía Fabril Financiera. ${ }^{18}$ El crecimiento del emblemático edificio de la calle California fue acompañado por continuas ampliaciones hasta fines de los '60, cuando alcanzó a completar la superficie de dos manzanas y varios pisos de alto que conservó hasta que sobrevino la quiebra definitiva en los noventa, con el remate del edificio y su posterior reconversión en un complejo inmobiliario de oficinas y depósito para mercaderías.

\section{Las inversiones}

Con el objetivo de analizar la evolución de las inversiones en la actividad gráfica hemos construido la cuenta "taller gráfico", constituida por las inversiones realizadas en terreno, edificio y maquinaria.

El Gráfico 1 muestra tres ciclos de inversiones (1903-1904, 19061908, 1911-1913), seguidos los dos primeros de pronunciadas caídas, que podemos explicar por las fuertes amortizaciones realizadas sobre las maquinarias. Por ejemplo, las inversiones de máquinas del ejercicio 1904, que ascendían a 187.723 pesos oro, fueron amortizadas totalmente en un solo ejercicio. La política de amortización fue sostenida a lo largo de un extenso período de doce años, desde 1907 hasta 1919, en los cuales no se registraron inversiones en maquinarias. La prolongada tendencia declinante de

18 En 1929 la CGF se dividió en dos sociedades: la Compañía General de Fósforos Sudamericana y la Compañía General Fabril Financiera. Esta última mantuvo los negocios de aceite vegetal, algodón, textil, papel e imprenta. Véase Compañía General Fabril Financiera, Memoria (1930) y Estatutos (1936). 
la curva desde 1914 hasta 1919 debe explicarse por la incidencia que tuvo para la adquisición de equipamiento la compleja coyuntura internacional de la Primera Guerra Mundial. Consideramos que en el desarrollo de la cuenta fábrica el factor preponderante fue la práctica de realizar fuertes amortizaciones desarrollada por la Sociedad Anónima, que castigaba en sus balances generales al capital físico, como cuestionaran en distintas oportunidades los accionistas: "por la razón que los balances no reflejan con exactitud la verdadera situación de la Sociedad estando en los mismos en un peso moneda nacional todas las maquinarias, los muebles y útiles y con el valor de adquisición los inmuebles". ${ }^{19}$

\section{GRÁFICO 1}

Evolución de la cuenta “Taller Gráfico", 1889-1918 (en pesos oro)

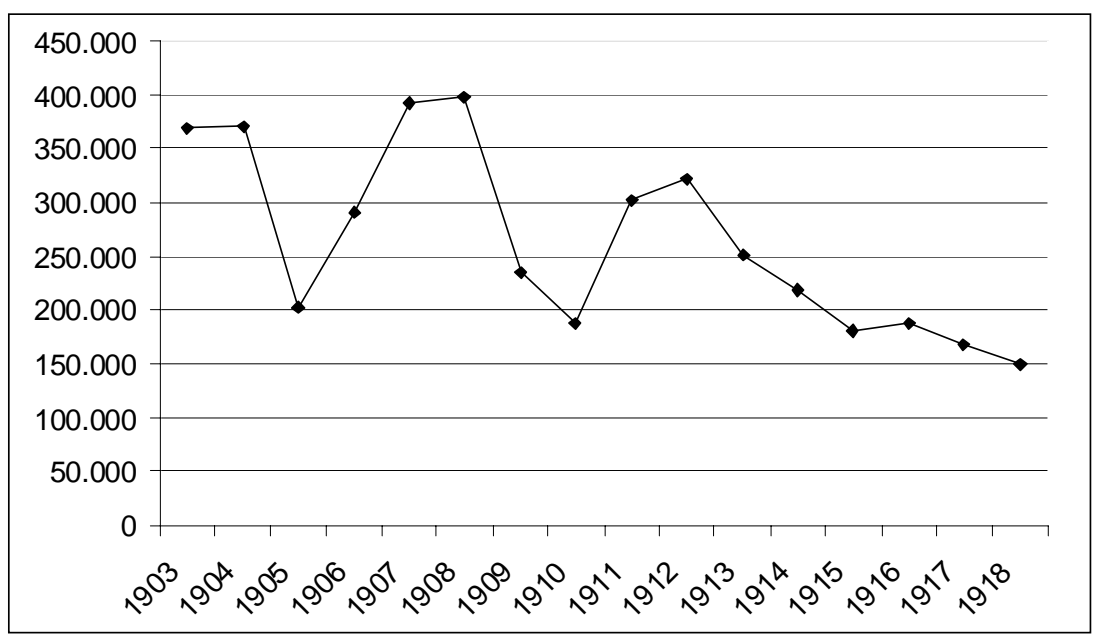

FUENTE: Elaboración propia en base a los Libros de Inventarios de la Compañía General de Fósforos, 1903-1919. Las cifras fueron deflactadas a partir de las cotizaciones del peso moneda nacional y peso oro brindado por Juan Alvarez, Temas de historia económica argentina, Buenos Aires, 1929.

Las importantes amortizaciones realizadas en esos años, que no se limitaban a las inversiones en el taller gráfico sino en el conjunto de la compañía, implicaron grandes reducciones en los beneficios netos y en la distribución de dividendos.

19 Vigésimo Cuarta Asamblea Ordinaria, 26 de marzo de 1913. En: Compañía General de Fósforos, Libros de Actas de Asambleas de Accionistas, Folio 31. 
La cuenta maquinaria y herramientas, que es la que mejor refleja la evolución de las inversiones, no pudo reconstruirse debido a las amortizaciones realizadas. ${ }^{20}$ Por lo tanto, reconstruimos las incorporaciones anuales realizadas en maquinarias a lo largo del período. En el Gráfico 2, se aprecian tres momentos de inversiones. El primero abarcó aproximadamente desde 1904 a 1907, con elevadas incorporaciones anuales. Este primer período fue seguido por una brusca caída en 1908. Hay un breve repunte en el año 1909, coincidente con la compra de una costosa tecnología de punta: la máquina rotativa offset tipográfica. Por último, un tercer ciclo de compra de maquinaria, entre los años 1911 y 1913, que presentó ciertas fluctuaciones en el ritmo de incorporaciones. Los dos últimos ciclos no alcanzaron los niveles de inversiones registrados para el primero. La caída de 1914 se prolongó durante la guerra; si bien las inversiones no desaparecieron, fueron poco significativas.

\section{GRÁFICO 2}

Incorporación anual de maquinaria (en pesos oro)

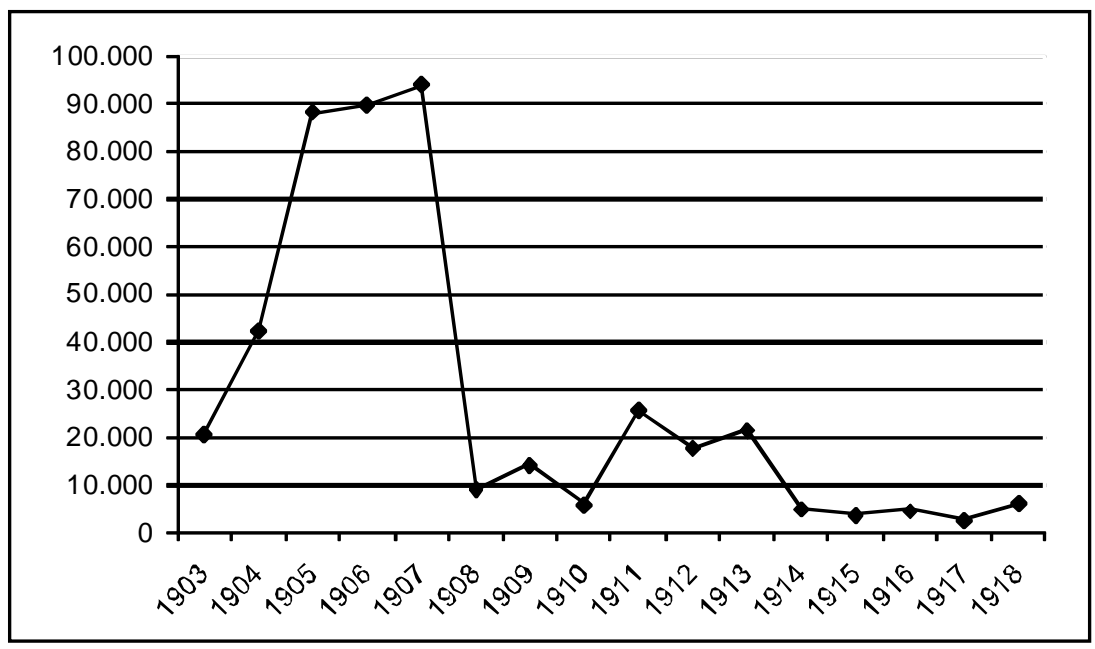

FUENTE: Elaboración propia en base a los Libros de Inventarios de la Compañía General de Fósforos, 1903-1919. Las cifras fueron deflactadas a partir de las cotizaciones del peso moneda nacional y peso oro brindado por Juan Alvarez, Temas de historia económica argentina, Buenos Aires, 1929.

20 Hasta 1925 no hubo una normativa sobre los criterios de amortización, esta situación cambia a partir de esa fecha cuando la Inspección General de Justicia reglamentó las amortizaciones y la confección de los balances de las sociedades anónimas. 
Una primera conclusión a partir de la evidencia presentada nos permite sostener que los empresarios no tuvieron una actitud remisa a invertir en maquinaria. En términos generales, el afán inversor fue motivado por alcanzar un lugar de preponderancia en el mercado. Destacamos que entre 1903 y 1911 las compras de maquinarias estuvieron destinadas tanto a equipamiento de la tipo-litografía como de la sección fabricación de cajitas. Las incorporaciones de equipamiento de la sección cajitas estuvieron centradas en operaciones ya mecanizadas y en la automatización de otras tareas aún manuales, siendo las más significativas: máquinas cortadoras, etiquetadoras y estampilladoras, además de los equipos de armado del interior y exterior de las cajas. ${ }^{21}$

En las artes gráficas propiamente dichas, las inversiones en modernas tecnologías fueron importantes y estuvieron dirigidas a dotar a la sección comercial de maquinaria para los procesos de composición, impresión y encuadernación, ampliando el rango y calidad de los productos manufacturados, asegurando una rápida impresión y un aumento en la escala de producción. ${ }^{22}$

La integración de las monotipos en la sala de composición permitió eliminar el desfasaje que se producía entre la parte mecanizada de la impresión y el lento proceso de composición manual. La monotipo fue utilizada para la composición de libros, tablas, trabajos científicos y catálogos. El proceso de mecanización también afectó a la encuadernación, con la incorporación de máquinas cosedoras de pliegos, abrochadoras, guillotinas y dobladoras automáticas. Las compras de equipos y maquinarias durante el primer ciclo de inversiones también estuvieron ligadas a la incorporación de procesos productivos ${ }^{23}$ - fotocomposición - y a la apertura de nuevas líneas productivas.

21 En 1911 cuando desmontaron la sección fabricación cajitas de Barracas transfirieron a Avellaneda las siguientes máquinas: 27 trazadoras, 38 máquinas de armar interiores; 41 armar exteriores, 56 gomitas interiores, 91 gomitas exteriores, 1 pegar etiquetas, 3 pegar gomitas y etiquetas, 2 máquinas cortar etiquetas, entre otras.

22 Entre la maquinaria incorporada encontramos las siguientes: 3 rotativas litográficas, una de ellas offset, 7 máquinas impresoras, una con ponepliego automático (alimentación mecánica del papel). En la impresión tipográfica incorporaron aproximadamente 13 minervas de distintos formatos, utilizadas en la producción de trabajos de tarjetería y papel carta. Además 15 prensas planas de distintos formato, una a retiración y otra rotativa tipográfica. El proceso de mecanización también afectó a la encuadernación, con la incorporación de máquinas cosedoras de pliegos, abrochadoras, guillotinas y dobladoras automáticas.

23 Procedimientos de reproducción gráfica que comprende una o varias operaciones fotográficas. Desde fines del siglo XIX la fotografía se había tornado imprescindible para los procesos de reproducción de imágenes. 
En términos generales, los empresarios debieron invertir en maquinarias para competir en el mercado, posiblemente el único en que la Compañía no disfrutaba de una posición oligopólica en la oferta, como sucedía en papel y fósforos. Sin embargo, las inversiones de la Compañía tenían una posición destacada en el conjunto del sector.

\section{Composición y evolución de las ventas}

El Gráfico 3 muestra una tendencia positiva en el crecimiento de las ventas de los productos manufacturados del establecimiento de litografía. Esta tendencia comienza a acentuarse a partir de 1908, llegando a duplicar los montos de las ventas para 1913. Este hecho coincidió con innovaciones e inversiones cuyo resultado fue la ampliación de la gama de productos, el acrecentamiento de la cartera de clientes, y el incremento de los volúmenes de mercaderías manufacturas destinados al mercado. La participación de las ventas de la sección comercio fueron siempre altas en relación con los totales del establecimiento. El año 1904 fue el último en que participó con el 100\% de las ventas. La incorporación de otras secciones, con

\section{GRÁFICO 3}

Ventas totales en pesos oro de la Litografía

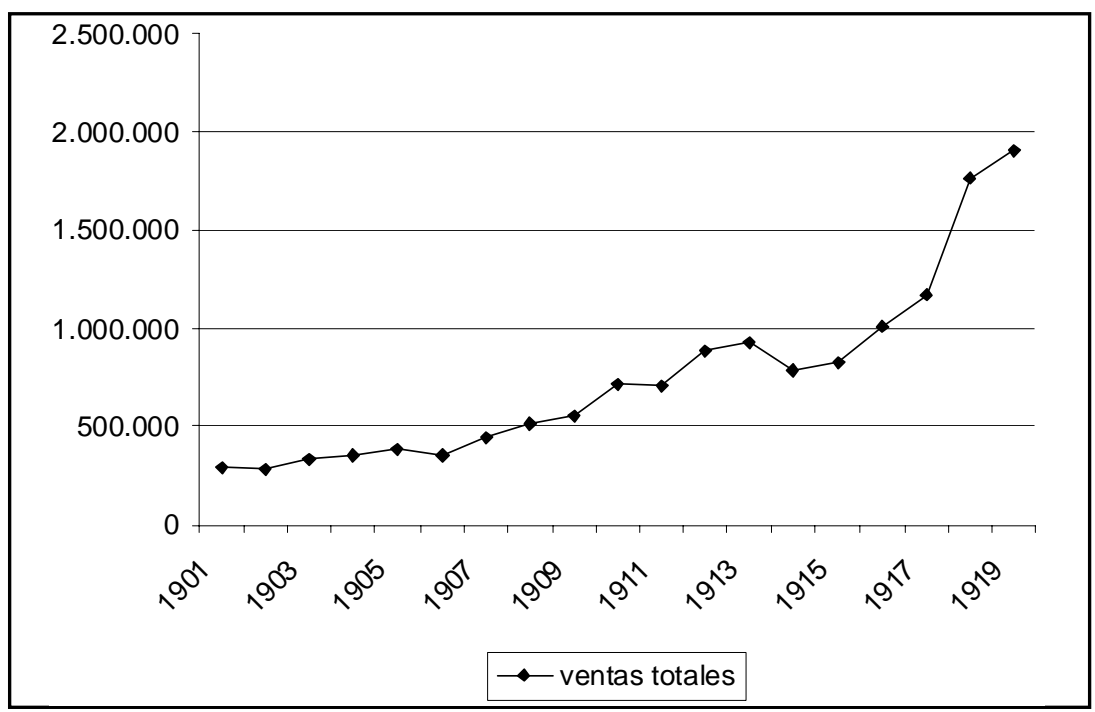

FUENTE: elaboración propia en base a Compañía General de Fósforos, Estadísticas generales, 1903-1919. 
nueva gamas de productos, redujo desde 1905 su participación, aunque siempre se mantuvo por encima del 70\%, salvo en 1915 $(68,7 \%)$ y en $1917(65,9 \%)$, descensos motivados por los efectos adversos de la contienda mundial sobre la economía del país.

¿Qué producía? ¿Quiénes eran sus clientes? Desde principios de siglo imprimían etiquetas para cigarros, caramelos y cerveza; estuches para yerba, turrones y jabones; envoltorios y fajas para tabaco, chocolates. Contaban entre sus principales clientes las firmas líderes del país, como Quilmes, Canale, Godet y Noël, entre otras. La firma Conen, del Grupo Tornquist, era la principal adquirente de los cartuchos para velas. La Sección Comercial acrecentó a lo largo de estos años la cartera de clientes. Para 1910, entre los más destacados figuraban las tiendas departamentales A La Ciudad de Londres y Gath y Chaves; empresas dedicadas a la producción de bebidas: Naranjiu, Giol y Gargantini, López Escorihuela, Cervecería Quilmes, Bieckert y en 1915 la Cervecería San Carlos. También fabricaban las cajas de Mitre y Popular, dos marcas de la Compañía General de Tabacos; cajas, marquillas y envoltorios para la Compañía Tabacalera Argentina y las marquillas de los cigarrillos 43 de Piccardo y Cía. En el rubro de la alimentación incorporaron, entre las firmas industriales más importantes del mercado, a Bagley, Café Paulista, Arrocera y Almidonera Argentina, La Industrial Paraguaya (yerba mate Flor de Lis). La sección cuadernos, libros en blanco y rayado participó, un año después de la instalación (1907), en las licitaciones de varias agencias estatales: Consejo Nacional de Educación, Dirección de Correos, Intendencia de Guerra y Banco Nación (1909). ${ }^{24}$

Las ventas de la sección comercio continuaron con un desempeño exitoso en el largo plazo, correspondiéndole un 95\% de la facturación total del ejercicio 1929-1930, mostrando el fuerte incremento de su peso en el conjunto de la facturación del taller gráfico. Pero más significativo es el peso de la facturación del taller gráfico en el contexto de la formación de la nueva Compañía General Fabril Financiera. En su primer ejercicio de 1929-1930 correspondió al taller gráfico el $64 \%$ de la facturación sobre el total del conjunto industrial. ${ }^{25}$

24 La sección fabricaba: libros diarios, mayores numerados, de actas, copiadores, borradores, libretas, índices, entre otros. En 1915 fabricaban para el Correo los libros de oficina, libros formularios de valijas y libros clasificación de valijas.

25 Compañía General Fabril Financiera, Libro de Actas de Directorio, Acta 25, 25 de junio de 1929. 


\section{Conclusiones}

La Compañía General de Fósforos fue una de las primeras grandes empresas que, a partir de la elaboración un producto masivo, de muy bajo costo y destinado al mercado interno, demostró un interés temprano por el desarrollo de una integración industrial. Ese eslabonamiento productivo estuvo ligado, en una primera etapa, a la implantación del taller gráfico para sustituir los estuches de fósforos, hasta entonces de procedencia europea, y a la manufactura de insumos - papel y cartulinas - para las cajas, con la instalación en 1903 de la fábrica de papel en Bernal.

El dinamismo empresarial quedó expresado en la instalación del taller gráfico, un hecho que los hizo distinguir y alcanzar ventajas frente al resto de los productores locales de fósforos que dependían, para la fabricación de las marquillas, de los establecimientos litográficos que funcionaban en la ciudad de Buenos Aires. Pero que al mismo tiempo constituyó, como señalamos, un hecho excepcional de inserción en la rama gráfica vía la integración vertical.

Este taller, originariamente un anexo del establecimiento fosforero de Barracas al Norte, fue transformándose desde principios del siglo XX, por la estrategia empresarial orientada a impulsar el acrecentamiento de sus intereses en la industria gráfica, hasta llegar a ser en 1911 una unidad productiva independiente con destacada presencia en el mercado.

La evolución de las inversiones y de las ventas, de tendencia francamente positiva, muestra que la estrategia seguida por la empresa fue exitosa en la transformación del establecimiento, permitiendo una diversificación productiva con la finalidad de satisfacer nuevas necesidades del mercado local. En particular, las inversiones en tecnología estuvieron destinadas a mecanizar tareas hasta entonces manuales y apuntaron también a la innovación de procesos y productos. Los indicadores utilizados muestran que en el período 1889-1921 los empresarios tuvieron una actitud innovadora y nada reticente a la hora de invertir en construcciones fabriles y maquinarias, ubicando al establecimiento entre los más competitivos del sector, aunque sin una posición preponderante como tenían en las ramas del papel y fósforos.

La política de diversificación seguida por la Compañía fue importante y significó desde 1905 la apertura de nuevas secciones para el desarrollo de otras líneas productivas. Sin embargo y al 
mismo tiempo, se mantuvo dentro de los rubros correspondientes al sector comercial de la imprenta: publicidad, guías, catálogos, etiquetas de cigarrillos, naipes, tarjetas, libros en blanco y rayados, almanaques, etc. Es decir, una producción relacionada con la actividad industrial, comercial y bancaria, que como señalamos había permitido la expansión de la rama entre fines del siglo XIX y principios del $X X$ y el crecimiento de ciertas empresas. Es un tipo de producción que, si bien alcanzaba grandes escalas en los establecimientos de mayor dimensión, entre los cuales se encontraba la Compañía, no tenía las características de una producción en serie, pues debía atender los requerimientos de sus clientes para los distintos productos. La Compañía diversificó la línea de producción hacia la confección de revistas en la década del '20, cuando la expansión de la industria cultural tornó muy rentable la entrada en el negocio de este tipo de publicaciones. 